\title{
$X$-ray fluorescence analysis of long-term changes in the levels and distributions of trace elements in the rat brain following mechanical injury
}

\author{
J. Chwiej · A. Sarapata $\cdot$ K. Janeczko • \\ Z. Stegowski $\cdot$ K. Appel $\cdot$ Z. Setkowicz
}

Received: 21 June 2010/Accepted: 13 October 2010/Published online: 4 November 2010

(C) The Author(s) 2010. This article is published with open access at Springerlink.com

\begin{abstract}
This paper describes the results of the application of X-ray fluorescence microscopy to the qualitative, topographic and quantitative elemental analysis of nervous tissue from rats with neocortical brain injury. The tissue samples were analyzed with a $15 \mu \mathrm{m}$ beam defined by the size of the polycapillary focus. Raster scanning of the samples generated 2D cartographies, revealing the distributions of elements such as $\mathrm{P}, \mathrm{S}, \mathrm{Cl}, \mathrm{K}, \mathrm{Ca}, \mathrm{Fe}, \mathrm{Cu}$, and $\mathrm{Zn}$. Special emphasis was placed on the analysis of the areas neighboring the lesion site and the hippocampal formation tissue. The results obtained for rats with mechanical brain injuries were compared with those recorded for controls and animals with pilocarpine-induced seizures. There were no significant differences in the elemental compositions of gray and white matter between injured and uninjured brain hemispheres. A higher level of Ca was observed in the gray matter of both of the hemispheres in brains with neocortical injuries. A similar relation was noticed for $\mathrm{Fe}$ in the white matter. A comparative study of hippocampal formation tissue showed a statistically significant decrease in the
\end{abstract}

J. Chwiej $(\bowtie) \cdot$ A. Sarapata $~ Z$ Z. Stegowski

Department of Medical Physics and Biophysics,

Faculty of Physics and Applied Computer Science,

AGH-University of Science and Technology,

Kraków, Poland

e-mail: jchwiej@novell.ftj.agh.edu.pl

K. Janeczko $\cdot$ Z. Setkowicz

Department of Neuroanatomy,

Institute of Zoology,

Jagiellonian University,

Kraków, Poland

K. Appel

Deutsches Elektronen-Synchrotron (DESY),

Hamburg, Germany mass per unit area of $\mathrm{P}$ in the dentate gyrus (DG) and the hilus $(\mathrm{H})$ of DG for animals with brain lesions in comparison with the control group. Analogous relations were found for $\mathrm{Cu}$ in the DG and $\mathrm{Zn}$ in sector 3 of Ammon's horn (CA3) and the DG. It is important to note that identical changes in the same areas were observed for animals with pilocarpine-induced seizures in our previous study.

Keywords Mechanical brain injury · Pilocarpine-induced seizures - Trace elements - Topographic and quantitative elemental analysis - X-ray fluorescence microscopy . Synchrotron radiation

\section{Introduction}

A mechanical brain injury destroys nerve cells and their connections, and leads to transitory or irreversible impairment of functional subsystems within the surrounding areas [1]. Moreover, the blood-brain barrier, which under normal conditions protects nervous tissue from direct external influences, is broken [2,3]. Consequently, the homeostasis of nerve and glial cells is interrupted.

According to clinical studies, epilepsy is a common outcome of brain injuries, and almost $50 \%$ of patients with penetrating brain injuries (traffic accidents, missile wounds) develop seizures $[4,5]$. The present paper is the continuation of our previous investigation concerning the role of trace elements in the pathogenesis and progress of epileptic seizures [6]. In the paper by Chwiej et al. [6] from 2008 , changes in the levels and distributions of $\mathrm{Ca}, \mathrm{Cu}, \mathrm{Zn}$ and $\mathrm{Br}$ in the rat brain experiencing pilocarpine-induced seizures were described. As has been frequently reported, trace elements play important roles in processes underlying the function of the normal brain. For example, $\mathrm{Zn}$ is 
strongly involved in the regulation of neuronal metabolism [7-10]. On the other hand, increased $\mathrm{Zn}$ levels can be cytotoxic and responsible for neuronal death [11, 12].

In the study described in this paper, we intended to verify if an increased susceptibility of the injured brain to epileptic seizures is associated with elemental anomalies located close to the lesion site and/or at longer distances. Because trace metals may participate in the processes involved in the neurodegenerative changes of the nervous tissue, elucidating the anomalies in their levels and distributions may be crucial to advancing our understanding of the processes that influence the functional modification of the brain as a result of simultaneous neurodegenerative and regenerative processes.

Our previous studies showed that elemental anomalies occurring in the brain are often limited only to selected anatomical structures. Because of this, it is necessary to take into account the spatial resolution that is achievable using the method chosen for elemental analysis. In this study, we used the synchrotron-based X-ray fluorescence (SRXRF) technique, which, besides micrometer spatial resolution, offers detection limits that are as good or even better than those possible to obtain using other methods of multielemental analysis [13-15]. The other advantages of SRXRF, such as high sensitivity, nondestructiveness, and the potential to simultaneously analyze many elements, provide a wide range of opportunities for its use as a tool for the multielemental imaging of thin tissue sections [16].

\section{Animals}

All animal-use procedures were approved by the Bioethical Commission of Jagiellonian University in accordance with international standards. Adult Wistar rats were obtained from an animal colony of the Institute of Pediatry, Collegium Medicum, Jagiellonian University, Krakow, and maintained under conditions of controlled temperature $\left(20 \pm 2{ }^{\circ} \mathrm{C}\right)$ and illumination (12-h light:12-h dark cycle). A solid diet (Labofeed) and water were available ad libitum.

\section{Brain lesioning}

Thirty-day-old male rats were anesthetized with pentobarbital (Vetbutal, Biowet, Poland, $30 \mathrm{mg} / \mathrm{kg}$ i.p.). Under aseptic conditions, a lesion was made in the left cerebral hemisphere by inserting a rotating dental drill down to the white matter underlying the cerebral cortex while avoiding complete perforation of the cerebral hemisphere wall. The depth of drill penetration into the brain was proportional to the brain size and was set using a limiting plastic ring fixed on the drill. The diameter of the drill was $1.2 \mathrm{~mm}$. Subsequently, the skin was sutured and the animals were

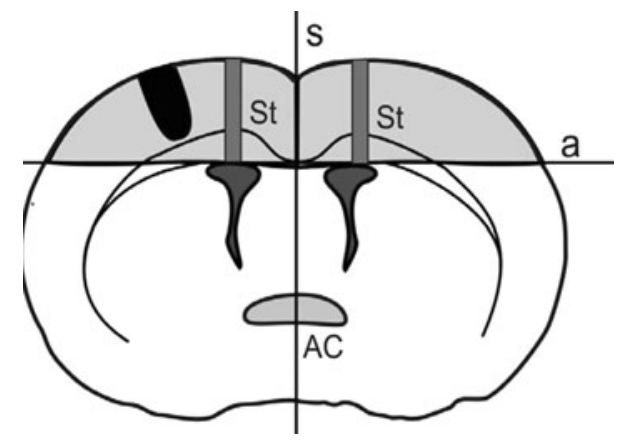

Fig. 1 The location of the lesion site in the rat brain

returned to their cages. Figure 1 shows the location of the lesion in the rat brain. This brain lesion model was used in our previous studies on glial response to injury $[17,18]$ and on its epileptogenic effects [19].

\section{Epilepsy induction}

The rats received a single i.p. injection of pilocarpine $(300 \mathrm{mg} / \mathrm{kg}$, Sigma P6503) on day 60 of their postnatal development. Scopolamine methyl bromide $(1 \mathrm{mg} / \mathrm{kg}$, Sigma S8502) was injected i.p. $30 \mathrm{~min}$ prior to pilocarpine to reduce its peripheral effects. Pilocarpine was injected between 9 and 10 a.m. to avoid circadian changes in seizure vulnerability.

The animals were continuously observed during a 6-h period. Motor symptoms were rated on a six-point scale used in our previous studies [20].

\section{Tissue preparation}

On day 60 of postnatal development all animals received a lethal dose of pentobarbital and were perfused transcardially with physiological saline solution of high analytical purity. The content of trace elements in the solution was additionally monitored using the total reflection X-ray fluorescence method at the X-ray Laboratory of the Department of Medical Physics and Biophysics (Faculty of Physics and Applied Computer Science, University of Science and Technology).

The brains were excised, frozen and cut using a cryomicrotome into $15-\mu \mathrm{m}$ thick slices. The specimens of the dorsal part of the hippocampus [21] were mounted on Ultralene foil and freeze-dried.

\section{Elemental analysis}

X-ray fluorescence microscopy was used for qualitative, quantitative and topographic elemental analysis of nervous 
tissue from rats with the mechanical brain injury. The measurements were done at HASYLAB beamline L. The energy of the exciting beam was set to $17 \mathrm{keV}$ and polycapillary optics was used as a focusing system, which allowed us to obtain a final beam spot of $15 \times 15 \mu \mathrm{m}$. A Vortex SDD detector from SII NanoTechnology USA Inc. was applied to measure the X-ray fluorescence spectra, and the acquisition time for each spectrum was $10 \mathrm{~s}$. Measurements of NIST standard reference materials (SRM 1833 and SRM 1832) were performed for spectrometer calibration.

\section{Results}

Two slices from each brain sample were examined using $\mathrm{X}$-ray fluorescence microscopy. The first section included the area of injury and the second the dorsal part of the hippocampal formation.

Sections with lesion areas were used to analyze the differences in elemental composition between the injured (IN) and uninjured (UI) hemispheres, as well as to compare the animals that had mechanical brain injuries with controls (C). Typical elemental maps obtained for such slice are presented in Fig. 2.
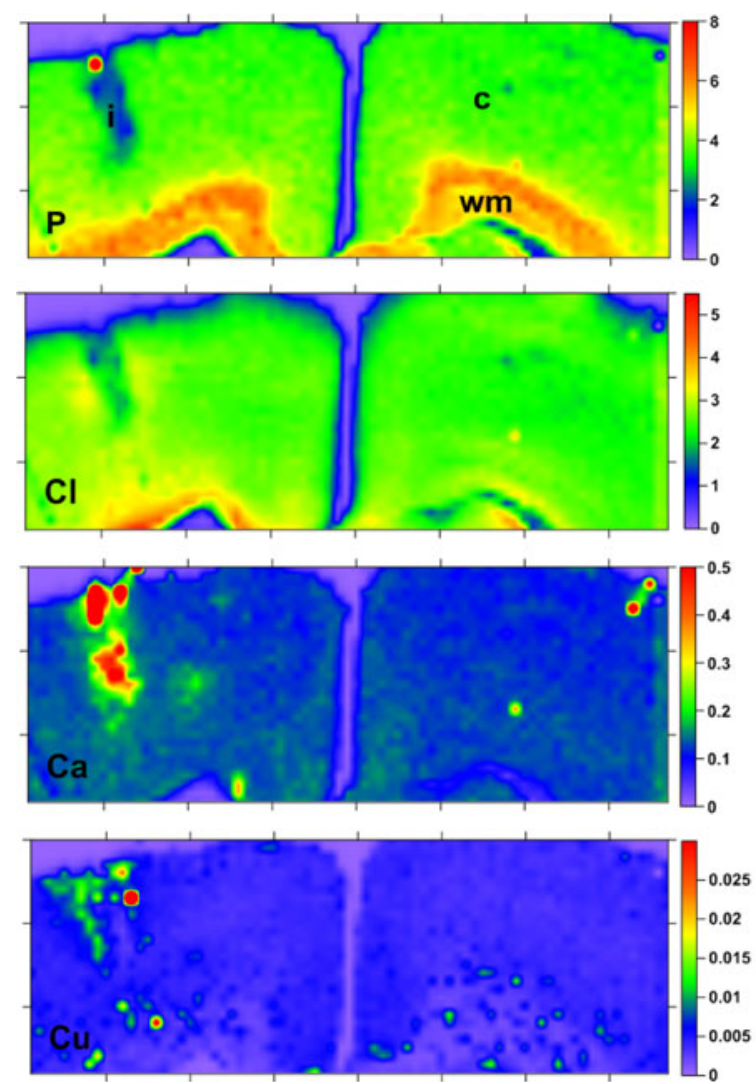

As one can notice in the Fig. 2, strong accumulation of metals such as: $\mathrm{Ca}, \mathrm{Fe}, \mathrm{Cu}$ was characteristic for the area of injury and/or the tissue closely adjacent to the lesion site. Obviously, the main source of these increased levels of $\mathrm{Fe}$ and $\mathrm{Ca}$ is the calcified hematoma that develops as a result of brain barrier disruption [22, 23]. However, because it cannot be excluded that such a result is also partially the consequence of the application of a dental drill in order to produce the brain damage, and this fact could significantly affect the obtained results, in subsequent quantitative analysis we decided to focus on brain structures that were not directly related to the tissue surrounding the damaged brain area.

The quantitative elemental analysis was performed in the way presented in our previous paper [6], and the mass per unit area of each element was calculated. Additionally, detection limits were evaluated for typical measurement conditions and all of the elements present in the tissue samples. The detection limits calculated for measurements of animals with mechanically injured brains were compared to those obtained previously for measurements of epileptic (SE) and control (C) groups (Table 1).

For the areas of gray (GM) and white matter (WM) (see Fig. 2), the mean masses per unit area of elements were
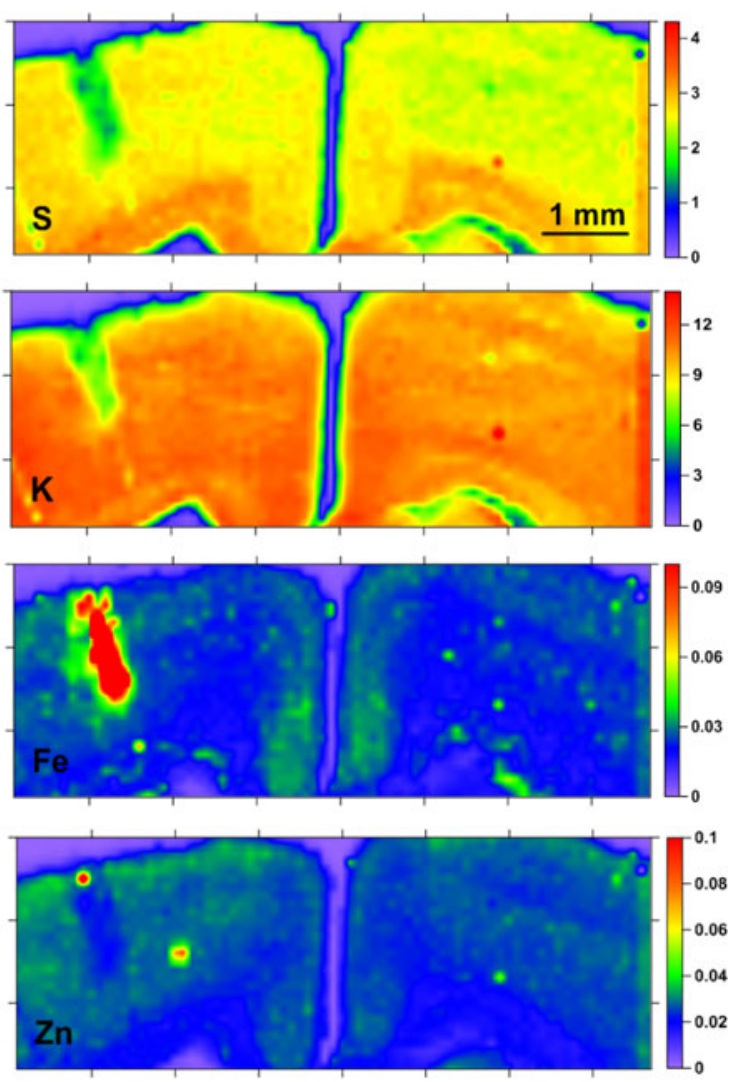

Fig. 2 Maps of elemental distribution (in each map, the colors indicate the mass per unit area of the element in question in $\mu \mathrm{g} / \mathrm{cm}^{2}$, as quantified by the scale to the right of each map) obtained for a section including an area of injury; $i$ the area of injury, $c$ gray matter, $w m$ white matter 
Table 1 Comparison between the elemental detection limits obtained during the measurements of IN and SE-C samples

\begin{tabular}{lcc}
\hline Elements & \multicolumn{2}{l}{ DL $(\mathrm{SD})$} \\
\cline { 2 - 3 } & IN samples & SE and C samples \\
\hline $\mathrm{P}$ & $0.231(0.007)$ & $0.256(0.008)$ \\
$\mathrm{S}$ & $0.081(0.001)$ & $0.104(0.003)$ \\
$\mathrm{Cl}$ & $0.0368(0.0006)$ & $0.053(0.001)$ \\
$\mathrm{K}$ & $0.0169(0.0002)$ & $0.027(0.001)$ \\
$\mathrm{Ca}$ & $0.0063(0.0001)$ & $0.0147(0.0008)$ \\
$\mathrm{Fe}$ & $0.00058(0.00003)$ & $0.00109(0.00004)$ \\
$\mathrm{Cu}$ & $0.0008(0.0001)$ & $0.00067(0.00003)$ \\
$\mathrm{Zn}$ & $0.0007(0.0001)$ & $0.00074(0.00003)$ \\
$\mathrm{Se}$ & $0.0007(0.0004)$ & $0.0017(0.0008)$ \\
$\mathrm{Br}$ & $0.000050(0.000003)$ & $0.00046(0.00002)$ \\
$\mathrm{Rb}$ & $0.00037(0.00002)$ & $0.00038(0.00003)$ \\
\end{tabular}

$D L$ the detection limit in $\mu \mathrm{g} / \mathrm{cm}^{2}, S D$ the uncertainties calculated at the $95 \%$ confidence level

evaluated. The typical sizes of the areas taken into account in the calculations were $500 \times 500$ and $300 \times 300 \mu \mathrm{m}^{2}$, respectively. The elements for which the average values were higher than the detection limits calculated for the nervous tissue ( $\mathrm{P}, \mathrm{S}, \mathrm{Cl}, \mathrm{K}, \mathrm{Ca}, \mathrm{Fe}, \mathrm{Cu}$ and $\mathrm{Zn}$ ) were taken into account in further analyses.

For all of the compared areas and groups, the median of the mean mass per unit area of each element was evaluated. The significance of any difference between median values was tested using the nonparametric Mann-Whitney $U$ test [24]. This particular statistical test was chosen due to the small size of the examined population (seven animals with mechanical brain injury, six epileptic, and five control cases examined), which did not allow us to test the normality of the distribution of the analyzed data. The results of the statistical analysis are shown in Fig. 3, while statistically significant differences between the analyzed areas of injured and control brains are summarized in Table 2 .

It is apparent from Fig. 3 that there were no significant differences in the elemental compositions of both gray and white matter between the injured and uninjured brain hemispheres. However, some anomalies were observed for animals with mechanical brain injuries in comparison with the control group. Lower levels of $\mathrm{P}(p=0.09)$ and $\mathrm{K}$ $(p=0.03)$ in gray matter from the uninjured hemisphere were observed for rats with mechanical brain injuries in comparison with the controls. For gray matter in both hemispheres, higher levels of $\mathrm{Ca}$ were observed in the mechanically injured brains. A similar relation was observed for $\mathrm{Fe}$ and the area of white matter.

The results obtained for sections including the dorsal part of the hippocampus were compared with the data recorded previously for epileptic and control groups [6]. In this case, the mean mass per unit area of each element was evaluated for four areas of hippocampal formation: sectors 1 and 3 of Ammon's horn (CA1 and CA3, respectively), the dentate gyrus (DG) and the hilus (H) of DG. The typical size of the compared areas was $300 \times 300 \mu \mathrm{m}^{2}$. The twodimensional distributions of the analyzed elements are presented in Fig. 4. Median values of the mean mass per unit area of each element in the examined areas from the three compared groups are shown in Fig. 5. Moreover, Table 3 shows the statistically significant differences that were found between the analyzed groups.

Statistically significant decreases in the mass per unit area of $\mathrm{P}$ in the DG $(p=0.06)$ and $\mathrm{H}(p=0.06)$ areas of hippocampal formation were observed for animals with brain lesions in comparison with those in the control group. Analogous relations were found for $\mathrm{Cu}$ in the DG $(p=0.02)$ and for $\mathrm{Zn}$ in the $\mathrm{CA} 3(p=0.02)$ and $\mathrm{DG}$ $(p=0.03)$ areas. It should also be mentioned that identical changes in exactly the same areas were previously observed for animals with pilocarpine-induced epilepsy.

The evaluation of the differences between rats with mechanical brain injuries and epileptic animals indicated significantly lower levels of Ca in the CA1 $(p=0.09)$ and DG $(p=0.05)$ hippocampal areas for the first examined group.

\section{Discussion and conclusions}

In this paper, the results of an elemental analysis carried out on mechanically injured rat brains are presented for the first time. As already shown [19], this injury produces a permanent modification of the brain structure, and thus significantly increases its susceptibility to seizure-inducing agents. According to clinical reports, approximately half of the patients who suffer a penetrating brain injury may also develop epilepsy [25-28]. Generally, the risk of posttraumatic epilepsy increases with lesion severity; nevertheless, epileptogenesis can also be triggered by very small lesions [29]. Other severe insults with strongly epileptogenic features include cerebrovascular diseases, such as stroke [30]. Finally, the occurrence of status epilepticus itself can also lead to epilepsy when evoked with different pathological conditions [30]. All of these forms of brain damage, despite their different inciting events, seem to share a common molecular mechanism, including an increase in extracellular glutamate concentration that leads to increased intracellular neuronal calcium and finally to neuronal injury and/or death [30].

During brain injury, as in epilepsy, interruption of the brain's blood supply leads to an ischemic and/or a hypoxic condition, which is/are characterized by a depletion of energy phosphates and a related failure of ionic pumps, 

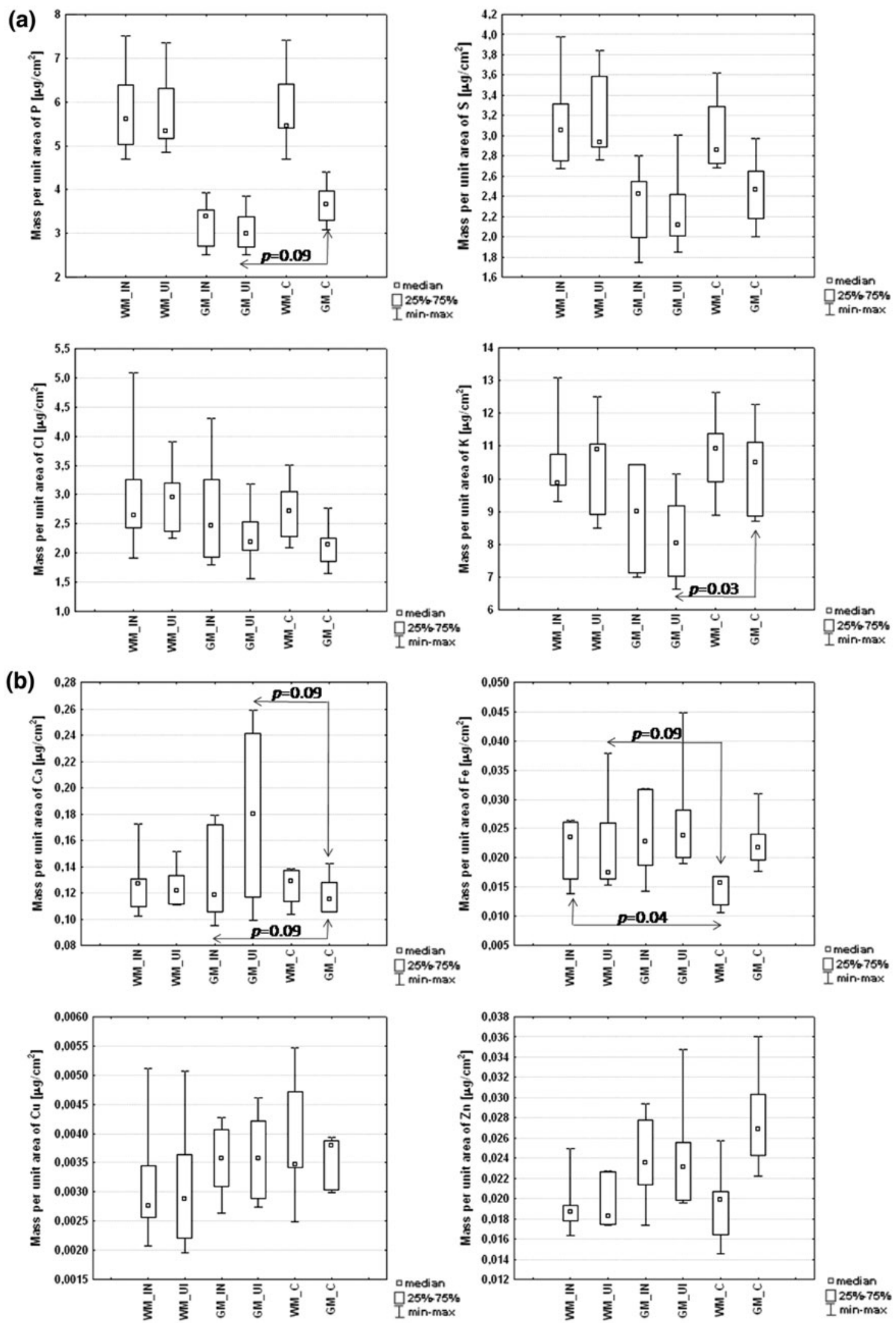

Fig. 3 Presentation of the median values of the mean mass per unit area of each element in gray (GM) and white matter (WM) from injured (IN) and uninjured (UI) brain hemispheres as well as in control (C) cases 
Table 2 Statistically significant differences between the analyzed areas of injured and control brains

\begin{tabular}{lllcl}
\hline Areas (I vs. II) & Element & $\begin{array}{l}\text { Content } \\
\text { in area I }\end{array}$ & $\begin{array}{l}\text { Content } \\
\text { in area II }\end{array}$ & $p$ value \\
\hline GM_UI vs. GM_C & P & 2.99 & 3.66 & 0.09 \\
GM_UI vs. GM_C & K & 8.04 & 10.49 & 0.03 \\
GM_IN vs. GM_C & Ca & 0.118 & 0.115 & 0.09 \\
GM_UI vs. GM_C & Ca & 0.180 & 0.115 & 0.09 \\
WM_IN vs. WM_C & Fe & 0.0235 & 0.0160 & 0.04 \\
WM_UI vs. WM_C & Fe & 0.0175 & 0.0160 & 0.09 \\
\hline
\end{tabular}

GM gray matter, $W M$ white matter, $U I$ uninjured hemisphere of injured brain, $I N$ injured hemisphere of injured brain, $C$ control brain

a The median value of the mean mass per unit area (in $\mu \mathrm{g} / \mathrm{cm}^{2}$ ) of the element in the compared area

increased extracellular potassium, neuronal depolarization, and the release of excitatory amino acids, such as glutamate [31]. Moreover, after a mechanical brain injury has been created in 1-month-old animals, as in our experiment, the glial scar constitutes a physical barrier that is impermeable to growing axons [32], making the restoration of damaged neural connections impossible. Within the region of the injury, many cells undergo apoptotic or necrotic changes. Some of them, however, can survive and create aberrant connections, underlying the increased susceptibility of the injured brain to spontaneous epileptic discharges or to seizuregenic stimuli, and finally facilitating the occurrence of status epilepticus. For these reasons, our current research focuses on the elemental analysis of injured and epileptic brains, in order to characterize common molecular pathways that underlie the described phenomena.

In our previous studies, we observed statistically significant changes in the accumulation of selected elements $(\mathrm{Ca}, \mathrm{Cu}$ and $\mathrm{Zn})$ in specific areas of the hippocampal formation and cortex after pilocarpine-induced seizures [6]. We also showed an increased susceptibility to seizures after a neocortical injury [19]. Therefore, it appeared reasonable to check if epileptogenic effects of penetrating brain injury were associated with elemental anomalies similar to those observed following pharmacologically induced status epilepticus.

The results obtained in this study did not confirm the existence of any statistically significant differences in the elemental compositions of gray and white matter between injured and uninjured brain hemispheres (despite the presence of the area of injury and the tissue closely adjacent to the lesion site in the gray matter). The comparison of animals with a brain lesion and the control group showed a lower level of $\mathrm{P}$ in gray matter of the uninjured hemisphere as well as in the $\mathrm{H}$ and DG sectors of hippocampal formation. In the first two of the above-mentioned areas, lower masses per unit area of $\mathrm{K}$ were also observed for animals with neocortical brain injury.

For animals with mechanical brain injury, increased mass per unit area of $\mathrm{Ca}$, as compared to controls, was observed for gray matter from both injured and uninjured brain hemispheres. In turn, such differences in $\mathrm{Ca}$ accumulation were not noticed for any of the analyzed hippocampal areas. The correlation of these observations with our previous findings concerning anomalies in $\mathrm{Ca}$ distribution occurring as a result of pilocarpine-induced SE (increased levels of $\mathrm{Ca}$ in the $\mathrm{CA} 1$ and $\mathrm{CA} 3$ hippocampal areas and the neocortex) seems to suggest that the role of $\mathrm{Ca}$ in the creation of epileptogenic discharges is limited to the areas that are the direct target for the epileptogenic factor.

The mass per unit area of $\mathrm{Fe}$ was significantly higher in the white matter of both hemispheres in animals with focal brain lesions comparing to controls. The most probable source of free iron is the lysis of red blood cells that are the
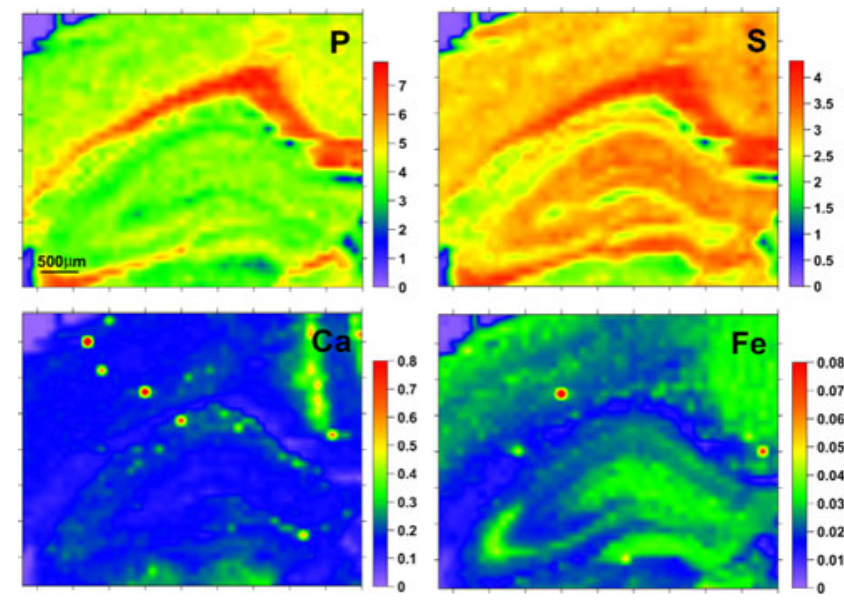
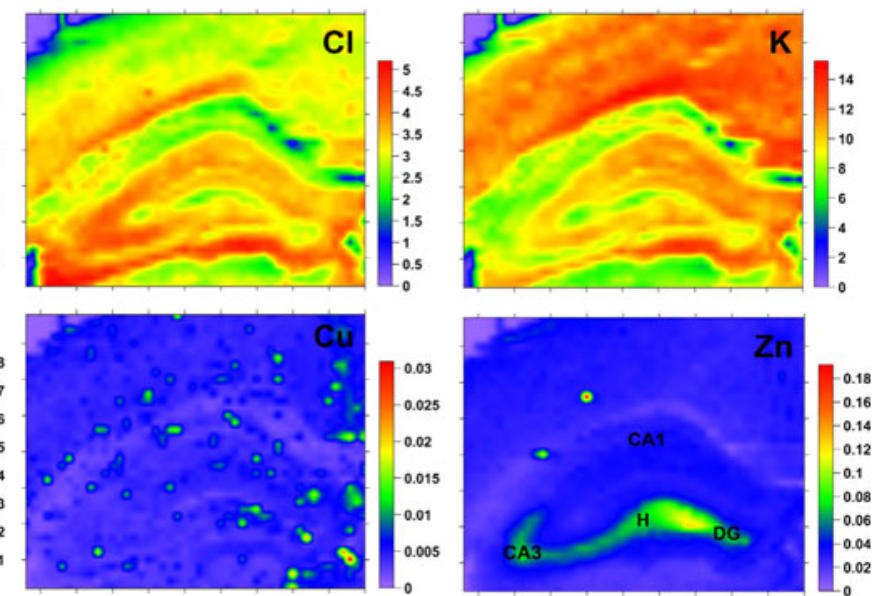

Fig. 4 Distributions of mass per unit area (in $\mu \mathrm{g} / \mathrm{cm}^{2}$ ) for selected elements recorded in animals with mechanically injured brains 

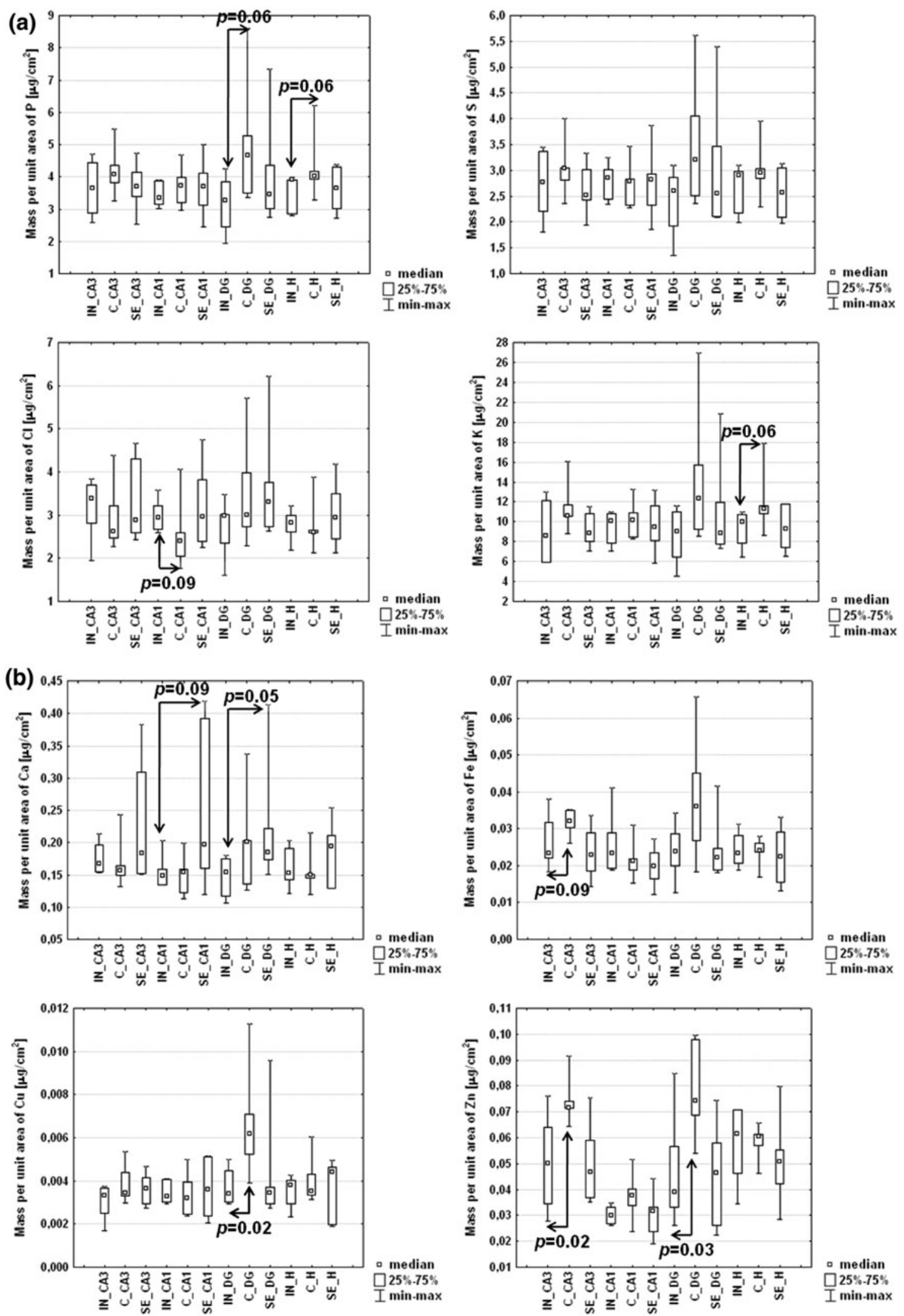

Fig. 5 Median values of the mean mass per unit area for elements in selected areas of hippocampal formation from animals with brain lesions (IN) and those in the epileptic (SE) and control (C) groups 
Table 3 Statistically significant differences found for the analyzed hippocampal areas between animals with brain injuries and those representing the epileptic and control groups

\begin{tabular}{lllcl}
\hline Areas (I vs. II) & Element & $\begin{array}{l}\text { Content } \\
\text { in area I }\end{array}$ & $\begin{array}{l}\text { Content } \\
\text { in area II }\end{array}$ & $p$ value \\
\hline DG_IN vs. DG_C & $\mathrm{P}$ & 3.26 & 4.66 & 0.06 \\
H_IN vs. H_C & $\mathrm{P}$ & 3.91 & 4.03 & 0.06 \\
H_IN vs. H_C & $\mathrm{K}$ & 9.99 & 11.29 & 0.06 \\
CA1_IN vs. CA1_SE & $\mathrm{Ca}$ & 0.148 & 0.197 & 0.09 \\
DG_IN vs. DG_SE & $\mathrm{Ca}$ & 0.154 & 0.185 & 0.05 \\
CA3_IN vs. CA3_C & $\mathrm{Fe}$ & 0.0233 & 0.0320 & 0.09 \\
DG_IN vs. DG_C & $\mathrm{Cu}$ & 0.00341 & 0.00619 & 0.02 \\
CA3_IN vs. CA3_C & $\mathrm{Zn}$ & 0.0500 & 0.0717 & 0.02 \\
DG_IN vs. DG_C & $\mathrm{Zn}$ & 0.0392 & 0.0742 & 0.03 \\
\hline
\end{tabular}

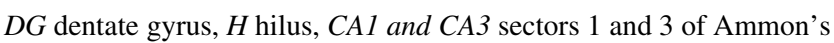
horn, $I N$ animal with mechanical brain injury, $S E$ animal with pilocarpine-induced seizures, $C$ control case.

${ }^{\text {a }}$ The median value of the mean mass per unit area (in $\mu \mathrm{g} / \mathrm{cm}^{2}$ ) of the element in the compared area

main component of a hematoma arising as a result of the blood-brain barrier disruption. The process of erythrocyte lysis occurs a few days after injury and involves the degradation of heme by heme oxygenase into iron, carbon monoxide, and biliverdin [33].

The most interesting findings seem to be the abnormalities in the distribution of $\mathrm{Cu}$ and $\mathrm{Zn}$ observed for the animals with brain lesions. The observed relations and their localizations are exactly the same for the animals with mechanical injury and pilocarpine-induced SE. This would suggest that these two metals, much more then $\mathrm{Ca}$, play a very important role in the common molecular pathways that finally lead to the acquired epilepsy.

These similarities were not, however, totally expected, because the brain injuries were made in 30-day-old animals and their long-term effects were observed 30 days later (i.e., on postnatal day 60), while seizures were induced in 60-day-old animals and their brains were taken for analysis $6 \mathrm{~h}$ after pilocarpine injection [6]. Therefore, it can be supposed that changes induced by acute seizures may accumulate on the basis of the pre-existing long-term postinjury changes, so they have an extra strong influence on the susceptibility to seizures observed in the previously injured brain [19].

The decreased level of $\mathrm{Zn}$ observed in the damaged brain at P30 confirms the results of Yeiser [34], who found that only neonatal brain damage increases the amount of $\mathrm{Zn}$ accumulation in response to injury, and so this accumulation appears to be highly age dependent.

The present study shows pathological changes in the elemental levels using selected but separate experimental paradigms (i.e., models of long-term effects of mechanical brain injury and of temporal lobe epilepsy involving pilocarpine-induced seizures). The results obtained raise a question about the possible contribution of the observed changes to the increased susceptibility to seizures observed in the injured brain. Therefore, the next step of our research is to further explore this problem using a combination of the two models to check the changes that actually occur following seizures induced in the previously injured brain.

Acknowledgments The research leading to these results received funding from the European Community's Seventh Framework Programme (FP7/2007-2013) under grant agreement no. 226716. This work was also supported by the Polish Ministry of Science and Higher Education and the following grants: 82/N-IA-SFS/2007/0, DESY-DII-20080009 EC, DS/BiNoZ/IZ/774/K/ZDS/000785. The first author is also grateful for support from the Foundation for Polish Science (Start Programme).

Open Access This article is distributed under the terms of the Creative Commons Attribution Noncommercial License which permits any noncommercial use, distribution, and reproduction in any medium, provided the original author(s) and source are credited.

\section{References}

1. Siesjo BK, Siesjo P (1996) Mechanisms of secondary brain injury. Eur J Anaesthesiol 13:247-268

2. Perry VH, Anthony DC, Bolton SJ, Brown HC (1997) The bloodbrain barrier and the inflammatory response. Mol Med Today 3:335-341

3. Martiney JA, Cuff C, Litwak M, Berman J, Brosnan CF (1998) Cytokine-induced inflammation in the central nervous system revisited. Neurochem Res 23:349-359

4. Feeney DM, Walker AE (1979) The prediction of posttraumatic epilepsy. A mathematical approach. Arch Neurol 36:8-12

5. Annegers JF, Coan SP (2000) The risks of epilepsy after traumatic brain injury. Seizure 9:453-457

6. Chwiej J, Winiarski W, Ciarach M, Janeczko K, Lankosz M, Rickers K, Setkowicz Z (2008) The role of trace elements in the pathogenesis and progress of pilocarpine-induced epileptic seizures. J Biol Inorg Chem 13:1267-1274

7. Fraker PJ, King LE, Laakko T, Vollmer TL (2000) The dynamic link between the integrity of the immune system and zinc status. J Nutr 130:1399-1406

8. Prasad AS (1995) Zinc: an overview. Nutrition 11:93-99

9. Prasad AS (2008) Zinc in human health: effect of zinc on immune cells. Mol Med 14:353-357

10. Rink L, Kirchner H (2000) Zinc-altered immune function and cytokine production. J Nutr 130:1407-1411

11. Koh TS, Peng RK, Klasing KC (1996) Dietary copper level affects copper metabolism during lipopolysaccharide-induced immunological stress in chicks. Poult Sci 75:867-872

12. Sensi SL, Jeng JM (2004) Rethinking the excitotoxic ionic milieu: the emerging role of $\mathrm{Zn}(2+)$ in ischemic neuronal injury. Curr Mol Med 4:87-111

13. Adams F, Janssens K, Snigirev A (1998) Microscopic X-ray fluorescence analysis and related methods with laboratory and synchrotron radiation sources. J Anal Atom Spectrom 13: 319-331 
14. Janssens KH, Rindby A, Adams F (2000) Microscopic X-ray fluorescence analysis. Wiley, Chichester

15. Snigireva I, Snigirev A (2006) X-ray microanalytical techniques based on synchrotron radiation. J Environ Monit 8:33-42

16. Szczerbowska-Boruchowska M (2008) X-ray fluorescence spectrometry, an analytical tool in neurochemical research. X-ray Spectrom 37:21-31

17. Janeczko K (1989) Spatiotemporal patterns of the astroglial proliferation in rat brain injured at the postmitotic stage of postnatal development: a combined immunocytochemical and autoradiographic study. Brain Res 485:236-243

18. Janeczko K (1994) Age-dependent changes in the proliferative response of S-100 protein-positive glial cells to injury in the rat brain. Int J Dev Neurosci 5:431-440

19. Setkowicz Z, Janeczko K (2003) Long-term changes in susceptibility to pilocarpine-induced status epilepticus following neocortical injuries in the rat at different developmental stages. Epilepsy Res 53:216-224

20. Setkowicz Z, Ciarach M, Guzik R, Janeczko K (2004) Different effects of neuroprotectants FK-506 and cyclosporin A on susceptibility to pilocarpine-induced seizures in rats with brain injured at different developmental stages. Epilepsy Res 61:63-72

21. Paxinos G, Watson C (1989) The rat brain in stereotaxic coordinates. Academic, San Diego

22. DiTullio MV, Stern WE (1979) Hemangioma calcificans. Case report of an intraparenchymatous calcified vascular hematoma with epileptogenic potential. J Neurosurg 50:110-114

23. Chen NF, Wang YC, Shen CC, Jan YJ, Chen WH, Leu CH (2004) Calcification and ossification of chronic encapsulated intracerebral haematoma. J Clin Neurosci 11:527-530
24. Robson C (1994) Experiment, design and statistics in psychology. Penguin, London

25. Salazar AM, Jabbari B, Vance SC, Grafman J, Amin D, Dillon JD (1985) Epilepsy after penetrating head injury. I. Clinical correlates: a report of the Vietnam Head Injury Study. Neurology 35:1406-1414

26. Feeney DM, Walker AE (1979) The prediction of posttraumatic epilepsy. A mathematical approach. Arch Neurol 36:8-12

27. Annegers JF, Coan SP (2000) The risks of epilepsy after traumatic brain injury. Seizure 9:453-457

28. Frey LC (2003) Epidemiology of posttraumatic epilepsy: a critical review. Epilepsia 44:11-17

29. Gottesman RF, Komotar R, Hillis AE (2003) Neurologic aspects of traumatic brain injury. Int Rev Psychiatry 15:302-309

30. DeLorenzo RJ, Sun DA, Deshpande LS (2005) Cellular mechanisms underlying acquired epilepsy: the calcium hypothesis of the induction and maintenance of epilepsy. Pharmacol Ther 105: 229-266

31. Franceschini D, Giusti P, Skaper SD (2006) MEK inhibition exacerbates ischemic calcium imbalance and neuronal cell death in rat cortical cultures. Eur J Pharmacol 553:18-27

32. Maxwell WL, Follows R, Ashhurst DE, Berry M (1990) The response of the cerebral hemisphere of the rat to injury. I. The mature rat. Philos Trans R Soc Lond B Biol Sci 26:479-500

33. Hua Y, Keep RF, Hoff JT, Xi G (2007) Brain injury after intracerebral hemorrhage: the role of thrombin and iron. Stroke 38:759-762

34. Yeiser EC, Lerant AA, Casto RM, Levenson CW (1999) Free zinc increases at the site of injury after cortical stab wounds in mature but not immature rat brain. Neurosci Lett 277:75-78 